Arq. Bras. Med. Vet. Zootec., v.68, n.4, p.1000-1006, 2016

\title{
Exigência de valina e isoleucina para codornas de corte no período de um a 14 dias e de 15 a 35 dias de idade
}

[Valine and isoleucine requirement for meat quails in the period of 1 to 14 days and of 15 to 35 days old]

E. Batista, A.C. Furlan, S.M. Marcato, P.C. Pozza, A.P.S. Ton, D.O. Grieser, V. Zancanela, C.E. Stanquevis, T.P. Perine, M.I. Benites, T.C. Euzébio, V.R.C. Paula

Universidade Estadual de Maringá - UEM - Maringá, PR

\begin{abstract}
RESUMO
Foram conduzidos dois experimentos, com o objetivo de estimar a exigência de valina e isoleucina digestível para codornas de corte em crescimento. No experimento 1 , foram utilizadas 2.160 codornas de corte de um dia de idade, não sexadas, distribuídas em um delineamento inteiramente ao acaso, com arranjo fatorial $4 \times 4$, sendo quatro níveis de valina digestível $(0,90,1,10,1,30$ e $1,50 \%)$ e quatro níveis de isoleucina digestível $(0,80,1,00,1,20$ e 1,40\%), totalizando 16 tratamentos, com três repetições e 45 codornas por unidade experimental. O peso corporal, o ganho de peso e a biomassa corporal acumulada aumentaram linearmente em função dos níveis de valina digestível e foram influenciados de forma quadrática, estimando $1,38 \%$ de isoleucina digestível. No experimento 2 , foram utilizadas 1.440 codornas de corte não sexadas, distribuídas em um delineamento inteiramente ao acaso, com arranjo fatorial $4 \times 4$, sendo quatro níveis de valina digestível $(0,82,1,02,1,22$ e $1,42 \%)$ e quatro níveis de isoleucina digestível $(0,73,0,93,1,13$ e $1,33 \%)$, totalizando 16 tratamentos, com três repetições e 30 codornas por unidade experimental. O desempenho de codornas de corte, no período de 15 a 35 dias de idade, não foi influenciado pelo aumento dos níveis de valina e isoleucina digestível nas rações experimentais. Concluise que as exigências de valina e isoleucina digestível para o máximo desempenho de codornas de corte, no período de um a 14 dias de idade, foram de $1,50 \%$ e $1,38 \%$, respectivamente, correspondendo às relações valina:lisina de $95 \%$ e isoleucina:lisina de $88 \%$. Os menores níveis avaliados, no período de 15 a 35 dias de idade, de $0,82 \%$ de valina digestível e de $0,73 \%$ de isoleucina digestível, correspondendo às relações valina:lisina de $52 \%$ e isoleucina: lisina de $46 \%$, foram suficientes para satisfazer as exigências nutricionais das codornas de corte sem comprometer o desempenho.
\end{abstract}

Palavras-chave: aminoácidos, antagonismo, balanceamento, Coturnix coturnix sp., desempenho

\begin{abstract}
Two experiments were carried out in order to estimate the requirements of digestible valine and isoleucine for growing meat quails. In experiment 1, 2160 meat quails with 1 day of age, not sexed, were used, distributed in a completely randomized design with a $4 \times 4$ factorial arrangement, with four levels of digestible valine $(0.90,1.10,1.30$, and $1.50 \%)$ and four levels of digestible isoleucine $(0.80,1.00,1.20$, and $1.40 \%)$, totaling 16 treatments with three replications and 45 quails per experimental unit. The body weight, the weight gain, and the accumulated body biomass linearly increased in function of digestible valine levels and were influenced in a quadratic way estimating $1.38 \%$ of digestible isoleucine. In experiment 2, 1440 meat quails, not sexed, were used, distributed in a completely randomized design with a $4 \times 4$ factorial arrangement, with four levels of digestible valine $(0.82,1.02,1.22$, and $1.42 \%)$ and four levels of digestible isoleucine $(0.73,0.93,1.13$, and $1.33 \%)$, totaling 16 treatments with three replications and 30 quails per experimental unit. The performance of meat quails from 15 to 35 days of age was not affected by increased levels of digestible valine and digestible isoleucine in the experimental diets. It was concluded that the requirements of digestible valine and digestible isoleucine for maximum performance
\end{abstract}

Recebido em 29 de setembro de 2015

Aceito em 8 de janeiro de 2016

E-mail: eliany_batista@hotmail.com 
of meat quail from one to 14 days of age were $1.50 \%$ and $1.38 \%$, respectively, corresponding to relations: valine: lysine of $95 \%$ and isoleucine: lysine of $88 \%$. The lower levels evaluated, in the period of 15 to 35 days old, $0.82 \%$ digestible valine and $0.73 \%$ of digestible isoleucine, corresponding to relations valine: lysine of $52 \%$ and isoleucine: lysine of $46 \%$ were sufficient to meet the nutritional requirements of meat quails without compromising performance.

Key word: amino acids, antagonisms, balancing, Coturnix coturnix sp, performance

\section{INTRODUÇÃO}

A criação de codornas de corte se destaca ano após ano como atividade produtiva no mercado agropecuário brasileiro $\mathrm{e}$ tem despertado $\mathrm{o}$ interesse de produtores e pesquisadores por não necessitar de grandes investimentos, por exigir pouco espaço para sua criação e reduzida mão de obra para sua manutenção, com retorno financeiro em curto ou médio prazo (Fugikura, 2002).

A alimentação representa mais de $70 \%$ do custo total da produção de codornas, existindo preocupação, por parte dos nutricionistas, em oferecer às aves rações com níveis nutricionais adequados para o máximo desempenho, com consequente retorno econômico (Freitas et al., 2006).

Outro fator importante refere-se às diferentes fases de alimentação das aves durante o período de crescimento, visto que as exigências nutricionais estabelecidas nas primeiras semanas de vida podem influenciar o desempenho e o rendimento no abate, havendo necessidade da realização de trabalhos direcionados para a determinação das exigências nutricionais nas fases inicial e final de crescimento. Ao se analisarem tabelas de exigências nutricionais disponíveis, fica clara a ausência de uniformidade nos períodos referidos para as diferentes fases de criação (Rezende et al., 2004).

A valina e a isoleucina são similares na estrutura e, juntamente com a leucina, pertencem ao grupo dos aminoácidos de cadeia ramificada. Também possuem funções fisiológicas semelhantes, entre elas encontram-se a regulação da tradução e o início da síntese de proteína em vários tecidos (Shimomura et al., 2006).

A proteína do milho possui quantidade relativamente baixa de valina e isoleucina e nível elevado de leucina. A grande quantidade de leucina nas rações pode aumentar as exigências de valina e isoleucina em frangos em crescimento e perus (Tutle e Balloun, 1976).

Segundo Garcia (2002), é necessário estabelecer exigências nutricionais para as codornas europeias e desenvolver programas de alimentação para maximizar o desempenho.

O objetivo deste estudo foi determinar a exigência nutricional de valina e isoleucina digestível, avaliando o desempenho de codornas de corte (Coturnix coturnix sp.) no período de um a 14 e de 15 a 35 dias de idade.

\section{MATERIAL E MÉTODOS}

Os experimentos foram realizados no setor de Coturnicultura da Fazenda Experimental de Iguatemi, da Universidade Estadual de Maringá, Maringá - PR.

No experimento 1, foram utilizadas 2.160 codornas de corte (Coturnix coturnix sp.) de um dia de idade, não sexadas, por um período experimental de um a 14 dias, alojadas em galpão convencional. $\mathrm{O}$ delineamento experimental utilizado foi $\mathrm{o}$ inteiramente ao acaso, de acordo com um arranjo fatorial $4 \times 4$, sendo quatro níveis de valina digestível $(0,90$, $1,10,1,30$ e $1,50 \%$ ) e quatro níveis de isoleucina digestível $(0,80,1,00,1,20$ e 1,40\%), totalizando 16 tratamentos, com três repetições e 45 codornas por unidade experimental.

As rações experimentais, à base de milho e farelo de soja, foram isoenergéticas, isocálcicas, isofosfóricas e isoaminoacídicas, exceto para valina e isoleucina (Tab. 1 e 2). Os aminoácidos metionina + cistina, treonina e triptofano foram balanceados seguindo a relação de proteína ideal estabelecida por Scherer (2009) e Ton (2010) para codornas de corte. As recomendações de $\mathrm{Ca}$ e P foram utilizadas segundo Silva et al. (2009), determinadas anteriormente, e os valores de composição química dos alimentos de acordo 
com Rostagno et al. (2011). O milho e o farelo de soja foram enviados a EVONIK Industries para a realização do aminograma, e, com base nos resultados, as rações foram formuladas.

Para a correção do balanço eletrolítico, foram adicionados diferentes proporções de bicarbonato de sódio $\left(\mathrm{NaHCO}_{3}\right)$ às rações experimentais. Os valores do balanço eletrolítico das rações experimentais foram calculados de acordo com Mongin (1981), considerando-se o peso molecular de cada elemento químico. das rações experimentais para posterior avaliação do desempenho zootécnico.

As codornas de corte foram avaliadas por meio das variáveis: peso final, ganho de peso, consumo de ração, conversão alimentar e biomassa corporal acumulada. A eutanásia dos animais foi realizada de acordo com as normas propostas pelo Comitê de Ética em Experimentação Animal da Universidade Estadual de Maringá (061 - PRO 024/2011 CEAE)

As aves foram pesadas semanalmente e, simultaneamente, foram realizadas as pesagens

Tabela 1. Composição percentual das rações experimentais para codornas de corte no período de um a 14 dias de idade

\begin{tabular}{|c|c|c|c|c|c|c|c|c|c|c|c|c|c|c|c|c|}
\hline \multirow{2}{*}{$\begin{array}{l}\text { Niveis de valina (\%) } \\
\text { Niveis de isoleucina (\%) } \\
\text { Ingredientes (\%) }\end{array}$} & \multicolumn{4}{|c|}{0,90} & \multicolumn{4}{|c|}{1,10} & \multicolumn{4}{|c|}{1,30} & \multicolumn{4}{|c|}{1,50} \\
\hline & 0,80 & 1,00 & 1,20 & 1,40 & 0,80 & 1,00 & 1,20 & 1,40 & 0,80 & 1,00 & 1,20 & 1,40 & 0,80 & 1,00 & 1,20 & 1,40 \\
\hline Milho grão & 55,63 & 55,63 & 55,63 & 55,63 & 55,63 & 55,63 & 55,63 & 55,63 & 55,63 & 55,63 & 55,63 & 55,63 & 55.63 & 55,63 & 5563 & 55.63 \\
\hline Soja farelo ( $45 \%)$ & 30,97 & 30,97 & 30,97 & 30,97 & 30,97 & 30,97 & 30,97 & 30,97 & 30,97 & 30,97 & 30,97 & 30,97 & 30,97 & 30,97 & 30,97 & 30,97 \\
\hline Ácido glutâmico & 3,53 & 3,28 & 3,03 & 2,79 & 3,24 & 2,99 & 2,75 & 2,50 & 2,95 & 2,71 & 2,46 & 2,21 & 2,68 & 2,43 & 2,19 & 1,94 \\
\hline Glúten de milho $(60 \%)$ & 3,00 & 3,00 & 3,00 & 3,00 & 3,00 & 3,00 & 3,00 & 3,00 & 3,00 & 3,00 & 3,00 & 3,00 & 3,00 & 3,00 & 3,00 & 3,00 \\
\hline Óleo de soja & 1,22 & 1,17 & 1,12 & 1,07 & 1,20 & 1,15 & 1,10 & 1,05 & 1,18 & 1,13 & 1,07 & 1,02 & 1,15 & 1,10 & 1,05 & 1,00 \\
\hline Fosfato bicálcico & 1,55 & 1,55 & 1,55 & 1,55 & 1,55 & 1,55 & 1,55 & 1,55 & 1,55 & 1,55 & 1,55 & 1,55 & 1,55 & 1,55 & 1,55 & 1,55 \\
\hline Calcário & 0,47 & 0,47 & 0,47 & 0,47 & 0,47 & 0,47 & 0,47 & 0,47 & 0,47 & 0,47 & 0,47 & 0,47 & 0,47 & 0,47 & 0,47 & 0,47 \\
\hline Sal comum & 0,11 & 0,11 & 0,11 & 0,11 & 0,11 & 0,11 & 0,11 & 0,11 & 0,11 & 0,11 & 0,11 & 0,11 & 0,11 & 0,11 & 0,11 & 0,11 \\
\hline Bicarbonato de sódio & 0,49 & 0,49 & 0,49 & 0,49 & 0,49 & 0,49 & 0,49 & 0,49 & 0,49 & 0,49 & 0,49 & 0,49 & 0,49 & 0,49 & 0,49 & 0,49 \\
\hline Suplemento $\mathrm{min} / \mathrm{vit}^{\prime}$ & 0,40 & 0,40 & 0,40 & 0,40 & 0,40 & 0,40 & 0,40 & 0,40 & 0,40 & 0,40 & 0,40 & 0,40 & 0,40 & 0,40 & 0,40 & 0,40 \\
\hline DL - metionina ( $99 \%)$ & 0,66 & 0,66 & 0,66 & 0,66 & 0,66 & 0,66 & 0,66 & 0,66 & 0,66 & 0,66 & 0,66 & 0,66 & 0,66 & 0,66 & 0,66 & 0,66 \\
\hline L - lisina $(78 \%)$ & 0,79 & 0,79 & 0,79 & 0,79 & 0,79 & 0,79 & 0,79 & 0,79 & 0,79 & 0,79 & 0,79 & 0,79 & 0,79 & 0,79 & 0,79 & 0,79 \\
\hline $\mathrm{L}-$ treonina $(98 \%)$ & 0,40 & 0,40 & 0,40 & 0,40 & 0,40 & 0,40 & 0,40 & 0,40 & 0,40 & 0,40 & 0,40 & 0,40 & 0,40 & 0,40 & 0,40 & 0,40 \\
\hline $\mathrm{L}$ - triptofano ( $(98 \%)$ & 0,14 & 0,14 & 0,14 & 0,14 & 0,14 & 0,14 & 0,14 & 0,14 & 0,14 & 0,14 & 0,14 & 0,14 & 0,14 & 0,14 & 0,14 & 0,14 \\
\hline $\mathrm{L}$ - isoleucina $(98 \%)$ & 0,00 & 0,20 & 0,41 & 0,61 & 0,00 & 0,20 & 0,41 & 0,61 & 0,00 & 0,20 & 0,41 & 0,61 & 0,00 & 0,20 & 0,41 & 0,61 \\
\hline $\mathrm{L}$ - valina (98\%) & 0,05 & 0,05 & 0,05 & 0,05 & 0,26 & 0,26 & 0,26 & 0,26 & 0,46 & 0,46 & 0,46 & 0,46 & 0,67 & 0,67 & 0,67 & 0,66 \\
\hline $\mathrm{L}$ - arginina (99\%) & 0,47 & 0,47 & 0,47 & 0,47 & 0,47 & 0,47 & 0,47 & 0,47 & 0,47 & 0,47 & 0,47 & 0,47 & 0,47 & 0,47 & 0,47 & 0,47 \\
\hline Antioxidante $^{2}$ & 0,01 & 0,01 & 0,01 & 0,01 & 0,01 & 0,01 & 0,01 & 0,01 & 0,01 & 0,01 & 0,01 & 0,01 & 0,01 & 0,01 & 0,01 & 0,01 \\
\hline Inerte & 0,12 & 0,22 & 0,31 & 0,40 & 0,23 & 0,32 & 0,41 & 0,51 & 0,33 & 0,43 & 0,52 & 0,61 & 0,44 & 0,53 & 0,62 & 0,71 \\
\hline Total & 100,00 & 100,00 & 100,00 & 100,00 & 100,00 & 100,00 & 100,00 & 100,00 & 100,00 & 100,00 & 100,00 & 100,00 & 100,00 & 100,00 & 100,00 & 100,00 \\
\hline
\end{tabular}

${ }^{1}$ Suplementação mineral/vitamínica (níveis de garantia por kg do produto); vit. A - 4.500.000UI; vit. D3 - 1.250.000UI; vit. E $4.000 \mathrm{mg}$; vit. B1 - 278mg; vit. B2 - 2.000mg; vit. B6 - 525mg; vit. B12 - 5.000mcg; vit. K3 - 1.007mg; pantotenato de cálcio $4.000 \mathrm{mg}$; niacina $-10.000 \mathrm{mg}$; colina $-140.000 \mathrm{mg}$; antioxidante $-5.000 \mathrm{mg}$; zinco $-31.500 \mathrm{mg}$; ferro $-24.500 \mathrm{mg}$; manganês $38.750 \mathrm{mg}$; cobre - 7.656mg; cobalto - 100mg; iodo - 484mg; selênio - 127mg; ${ }^{2} \mathrm{BHT}$ (butil-hidroxitolueno).

Tabela 2. Composição nutricional das rações experimentais para codornas de corte no período de um a 14 dias de idade

\begin{tabular}{|c|c|c|c|c|c|c|c|c|c|c|c|c|c|c|c|c|}
\hline \multirow{2}{*}{$\begin{array}{l}\text { Níveis de valina (\%) } \\
\text { Níveis de isoleucina (\%) }\end{array}$} & \multicolumn{4}{|c|}{0,90} & \multicolumn{4}{|c|}{1,10} & \multicolumn{4}{|c|}{1,30} & \multicolumn{4}{|c|}{1,50} \\
\hline & 0,80 & 1,00 & 1,20 & 1,40 & 0,80 & 1,00 & 1,20 & 1,40 & 0,80 & 1,00 & 1,20 & 1,40 & 0,80 & 1,00 & 1,20 & 1,40 \\
\hline Energia Metabolizável kcal $/ \mathrm{kg}$ & 2,997 & 2,997 & 2,997 & 2,997 & 2,997 & 2,997 & 2,997 & 2,997 & 2,997 & 2,997 & 2,997 & 2,997 & 2,997 & 2,997 & 2,997 & 2,997 \\
\hline Fósforo disponível (\%) & 0,41 & 0,41 & 0,41 & 0,41 & 0,41 & 0,41 & 0,41 & 0,41 & 0,41 & 0,41 & 0,41 & 0,41 & 0,41 & 0,41 & 0,41 & 0,41 \\
\hline Cálcio (\%) & 0,65 & 0,65 & 0,65 & 0,65 & 0,65 & 0,65 & 0,65 & 0,65 & 0,65 & 0,65 & 0,65 & 0,65 & 0,65 & 0,65 & 0,65 & 0,65 \\
\hline Proteína bruta (\%) & 25,00 & 25,00 & 25,00 & 25,00 & 25,00 & 25,00 & 25,00 & 25,00 & 25,00 & 25,00 & 25,00 & 25,00 & 25,00 & 25,00 & 25,00 & 25,00 \\
\hline Arginina digestivel (\%) & 1,73 & 1,73 & 1,73 & 1,73 & 1,73 & 1,73 & 1,73 & 1,73 & 1,73 & 1,73 & 1,73 & 1,73 & 1,73 & 1,73 & 1,73 & 1,73 \\
\hline Lisina digestivel (\%) & 1,60 & 1,60 & 1,60 & 1,60 & 1,60 & 1,60 & 1,60 & 1,60 & 1,60 & 1,60 & 1,60 & 1,60 & 1,60 & 1,60 & 1,60 & 1,60 \\
\hline Treonina digestivel (\%) & 1,07 & 1,07 & 1,07 & 1,07 & 1,07 & 1,07 & 1,07 & 1,07 & 1,07 & 1,07 & 1,07 & 1,07 & 1,07 & 1,07 & 1,07 & 1,07 \\
\hline Triptofano digestível (\%) & 0,36 & 0,36 & 0,36 & 0,36 & 0,36 & 0,36 & 0,36 & 0,36 & 0,36 & 0,36 & 0,36 & 0,36 & 0,36 & 0,36 & 0,36 & 0,36 \\
\hline Metionina+cistina digestivel (\%) & 1,26 & 1,26 & 1,26 & 1,26 & 1,26 & 1,26 & 1,26 & 1,26 & 1,26 & 1,26 & 1,26 & 1,26 & 1,26 & 1,26 & 1,26 & 1,26 \\
\hline Isoleuc & 0,80 & 1,00 & 1,20 & 1,40 & 0,80 & 1,00 & 1,20 & 1,40 & 0,80 & 1,00 & 1,20 & 1,40 & 0,80 & 1,00 & 1,20 & 1,40 \\
\hline Valina & 0,90 & 0,90 & 0,90 & 0,90 & 1,10 & 1,10 & 1,10 & 1,10 & 1,30 & 1,30 & 1,30 & 1,30 & 1,50 & 1,50 & 1,50 & 1,50 \\
\hline Leuc & 1,69 & 1,69 & 1,69 & 1,69 & 1,69 & 1,69 & 1,69 & 1,69 & 1,69 & 1,69 & 1,69 & 1,69 & 1,69 & 1,69 & 1,69 & 1,69 \\
\hline Cloro (\%) & 0,27 & 0,27 & 0,27 & 0,27 & 0,27 & 0,27 & 0,27 & 0,27 & 0,27 & 0,27 & 0,27 & 0,27 & 0,27 & 0,27 & 0,27 & 0,27 \\
\hline Sódio ( & 0,20 & 0,20 & 0,20 & 0,20 & 0,20 & 0,20 & 0,20 & 0,20 & 0,20 & 0,20 & 0,20 & 0,20 & 0,20 & 0,20 & 0,20 & 0,20 \\
\hline Potássio (\%) & 0,73 & 0,74 & 0,74 & 0,74 & 0,74 & 0,74 & 0,74 & 0,74 & 0,74 & 0,74 & 0,74 & 0,74 & 0,74 & 0,74 & 0,74 & 0,74 \\
\hline Balanço Eletrolítico $(\mathrm{mEq} / \mathrm{kg})$ & 199,74 & 199,84 & 199,94 & 200,01 & 199,84 & 199,94 & 200,01 & 200,12 & 199,94 & 200,04 & 200,14 & 200,24 & 200,07 & 200,17 & 200,24 & 200,35 \\
\hline
\end{tabular}

A análise estatística dos dados foi realizada por meio de regressão polinomial, utilizando-se o sistema para análises estatísticas - SAEG (versão 7.1).
As estimativas para valina e isoleucina digestível foram feitas por meio do modelo quadrático e/ou descontínuo "Linear Response Plateau" (LRP), conforme o ajustamento dos dados obtidos para cada variável. 
No experimento 2, foram utilizadas 1.440 codornas de corte (Coturnix coturnix sp.) de 15 dias de idade, não sexadas, alojadas no mesmo galpão utilizado no primeiro experimento. As aves utilizadas neste experimento foram as remanescentes do experimento anterior, e, aos 15 dias de idade, os animais foram pesados, divididos por classe de peso e distribuídos uniformemente nas unidades experimentais para que todos os tratamentos tivessem condições de igualdade de peso (Sakomura e Rostagno, 2007).

O delineamento experimental utilizado foi o inteiramente ao acaso, de acordo com um arranjo fatorial $4 \times 4$, sendo quatro níveis de valina digestível $(0,82,1,02,1,22$ e $1,42 \%)$ e quatro níveis de isoleucina digestível $(0,73,0,93,1,13$ e $1,33 \%$ ), totalizando 16 tratamentos, com três repetições e 30 codornas por unidade experimental.

As rações experimentais, à base de milho e farelo de soja, foram isoenergéticas, isocálcicas, isofosfóricas e isoaminoacídicas, exceto para valina e isoleucina (Tab. 3 e 4$)$.

Tabela 3. Composição percentual das rações experimentais para codornas de corte no período de 15 a 35 dias de idade

\begin{tabular}{|c|c|c|c|c|c|c|c|c|c|c|c|c|c|c|c|c|}
\hline \multirow{2}{*}{$\begin{array}{l}\text { Níveis de valina (\%) } \\
\text { Níveis de isoleucina (\%) }\end{array}$} & \multicolumn{4}{|c|}{0,73} & \multicolumn{4}{|c|}{0,93} & \multicolumn{4}{|c|}{1,13} & \multicolumn{4}{|c|}{1,33} \\
\hline & 0,82 & 1,02 & 1,22 & 1,42 & 0,82 & 1,02 & 1,22 & 1,42 & $\overline{0,82}$ & 1,02 & 1,22 & 1,42 & 0,82 & 1,02 & 1,22 & 1,42 \\
\hline \\
\hline Milho grão & 67,59 & 67,59 & 67,59 & 67,59 & 67,59 & 67,59 & 67,59 & 67,59 & 67,59 & 67,59 & 67,59 & 67,59 & 67,59 & 67,59 & 67,59 & 67,59 \\
\hline Soja farelo $(45 \%)$ & 22,81 & 22,81 & 22,81 & 22,81 & 22,81 & 22,81 & 22,81 & 22,81 & 22,81 & 22,81 & 22,81 & 22,81 & 22,81 & 22,81 & 22,81 & 22,81 \\
\hline Ácido glutâmico & 1,50 & 1,25 & 1,01 & 0,76 & 1,21 & 0,97 & $\begin{array}{l}0,72,01 \\
0,72\end{array}$ & 0,47 & 0,93 & 0,68 & $\begin{array}{c}2,401 \\
0,43\end{array}$ & $\begin{array}{r}2,01 \\
0,19\end{array}$ & 0,64 & $\begin{array}{l}22,01 \\
0,39\end{array}$ & $\begin{array}{l}2,01 \\
0,15\end{array}$ & 0,00 \\
\hline Glúten de milho $(60 \%)$ & 2,00 & 2,00 & 2,00 & 2,00 & 2,00 & 2,00 & 2,00 & 2,00 & 2,00 & $\begin{array}{l}0,00 \\
2,00\end{array}$ & $\begin{array}{l}0,43 \\
2,00\end{array}$ & 2,00 & $\begin{array}{l}0,04 \\
2,00\end{array}$ & 2,00 & 2,00 & 2,00 \\
\hline Óleo de soja & 0,08 & 0,03 & 0,00 & 0,00 & 0,06 & 0,01 & 0,00 & 0,00 & 0,04 & 0,00 & 0,00 & 0,00 & 0,01 & 0,00 & 0,00 & 0,00 \\
\hline Fosfato bicálcico & 1,61 & 1,61 & 1,61 & 1,61 & 1,61 & 1,61 & 1,61 & 1,61 & 1,61 & 1,61 & 1,61 & 1,61 & 1,61 & 1,61 & 1,61 & 1,61 \\
\hline Calcário & 0,47 & 0,47 & 0,47 & 0,47 & 0,47 & 0,47 & 0,47 & 0,47 & 0,47 & 0,47 & 0,47 & 0,47 & 0,47 & 0,47 & 0,47 & 0,47 \\
\hline Sal comum & 0,11 & 0,11 & 0,11 & 0,11 & 0,11 & 0,11 & 0,11 & 0,11 & 0,11 & 0,11 & 0,11 & 0,11 & 0,11 & 0,11 & 0,11 & 0,11 \\
\hline Bicarbonato de sódio & 0,56 & 0,56 & 0,56 & 0,56 & 0,56 & 0,56 & 0,56 & 0,56 & 0,56 & 0,56 & 0,56 & 0,56 & 0,56 & 0,56 & 0,56 & 0,56 \\
\hline $\begin{array}{l}\text { Bicarbonato de so } \\
\text { Suplemento } \mathrm{min} / \mathrm{v}\end{array}$ & $\begin{array}{l}0,46 \\
0,40\end{array}$ & $\begin{array}{l}0,56 \\
0,40\end{array}$ & $\begin{array}{l}0,46 \\
0,40\end{array}$ & $\begin{array}{l}0,56 \\
0,40\end{array}$ & $\begin{array}{l}0,40 \\
0,40\end{array}$ & $\begin{array}{l}0,46 \\
0,40\end{array}$ & $\begin{array}{l}0,56 \\
0,40\end{array}$ & $\begin{array}{l}0,46 \\
0,40\end{array}$ & 0,40 & $\begin{array}{l}0,46 \\
0,40\end{array}$ & $\begin{array}{l}0,56 \\
0,40\end{array}$ & $\begin{array}{l}0,56 \\
0,40\end{array}$ & $\begin{array}{l}0,56 \\
0,40\end{array}$ & $\begin{array}{l}0,56 \\
0,40\end{array}$ & $\begin{array}{l}0,46 \\
0,40\end{array}$ & $\begin{array}{l}0,56 \\
0,40\end{array}$ \\
\hline DL - metionina ( $99 \%)$ & 0,64 & 0,64 & 0,64 & 0,64 & 0,64 & 0,64 & 0,64 & 0,64 & 0,64 & 0,64 & 0,64 & 0,64 & 0,64 & 0,64 & 0,64 & 0,64 \\
\hline $\mathrm{L}-$ lisina $(78 \%)$ & 0,86 & 0,86 & 0,86 & 0,86 & 0,86 & 0,86 & 0,86 & 0,86 & 0,86 & 0,86 & 0,86 & 0,86 & 0,86 & 0,86 & 0,86 & 0,86 \\
\hline $\mathrm{L}$ - treonina (98\%) & 0,43 & 0,43 & 0,43 & 0,43 & 0,43 & 0,43 & 0,43 & 0,43 & 0,43 & 0,43 & 0,43 & 0,43 & 0,43 & 0,43 & 0,43 & 0,43 \\
\hline $\mathrm{L}-$ triptofano $(98 \%)$ & 0,15 & 0,15 & 0,15 & 0,15 & 0,15 & 0,15 & 0,15 & 0,15 & 0,15 & 0,15 & 0,15 & 0,15 & 0,15 & 0,15 & 0,15 & 0,15 \\
\hline $\mathrm{L}-\operatorname{arginina}(99 \%)$ & 0,57 & 0,57 & 0,57 & 0,57 & 0,57 & 0,57 & 0,57 & 0,57 & 0,57 & 0,57 & 0,57 & 0,57 & 0,57 & 0,57 & 0,57 & 0,57 \\
\hline $\mathrm{L}$-isoleucina & 0,09 & 0,30 & 0,50 & 0,70 & 0,09 & 0,30 & 0,50 & 0,70 & 0,09 & 0,30 & 0,50 & 0,70 & 0,09 & 0,30 & 0,50 & 0,70 \\
\hline L-vali & 0,12 & 0,12 & 0,12 & 0,12 & 0,33 & 0,33 & 0,33 & 0,33 & 0,53 & 0,53 & 0,53 & 0,53 & 0,74 & 0,74 & 0,74 & 0,74 \\
\hline Antioxic & 0,01 & 0,01 & 0,01 & 0,01 & 0,01 & 0,01 & 0,01 & 0,01 & 0,01 & 0,01 & 0,01 & 0,01 & 0,01 & 0,01 & 0,01 & 0,01 \\
\hline Inerte & 0,00 & 0,09 & 0,17 & 0,21 & 0,10 & 0,20 & 0,25 & 0,29 & 0,21 & 0,29 & 0,33 & 0,37 & 0,31 & 0,37 & 0,41 & 0,35 \\
\hline Total & 100,00 & 100,00 & 100,00 & 100,00 & 100,00 & 100,00 & 100,00 & 100,00 & 100,00 & 100,00 & 100,00 & 100,00 & 100,00 & 100,00 & 100,00 & 100,00 \\
\hline
\end{tabular}

${ }^{1}$ Suplementação mineral/vitamínica (níveis de garantia por kg do produto); vit. A - 4.500.000UI; vit. D3 - 1.250.000UI; vit. E $4.000 \mathrm{mg}$; vit. B1 - 278mg; vit. B2 - 2.000mg; vit. B6 - 525mg; vit. B12 - 5.000mcg; vit. K3 - 1.007mg; pantotenato de cálcio $4.000 \mathrm{mg}$; niacina $-10.000 \mathrm{mg}$; colina $-140.000 \mathrm{mg}$; antioxidante $-5.000 \mathrm{mg}$; zinco $-31.500 \mathrm{mg}$; ferro - 24.500mg; manganês $38.750 \mathrm{mg}$; cobre - 7.656mg; cobalto - 100mg; iodo - 484mg; selênio - 127mg; ${ }^{2}$ BHT (butil-hidroxitolueno).

Tabela 4. Composição nutricional das rações experimentais para codornas de corte no período de 15 a 35 dias de idade

\begin{tabular}{|c|c|c|c|c|c|c|c|c|c|c|c|c|c|c|c|c|}
\hline \multirow{2}{*}{$\begin{array}{l}\text { Níveis de valina (\%) } \\
\text { Niveis de isoleucina (\%) }\end{array}$} & \multicolumn{4}{|c|}{0,73} & \multicolumn{4}{|c|}{0,93} & \multicolumn{4}{|c|}{1,13} & \multicolumn{4}{|c|}{1,33} \\
\hline & 0,82 & 1,02 & 1,22 & 1,42 & 0,82 & 1,02 & 1,22 & 1,42 & 0,82 & 1,02 & 1,22 & 1,42 & 0,82 & 1,02 & 1,22 & 1,42 \\
\hline Energia Metabolizável (kcal/kg) & 3,036 & 3,036 & 3,036 & 3,036 & 3,036 & 3,036 & 3,036 & 3,036 & 3,036 & 3,036 & 3,036 & 3,036 & 3,036 & 3,036 & 3,036 & 3,036 \\
\hline Fósforo disponível (\%) & 0,41 & 0,41 & 0,41 & 0,41 & 0,41 & 0,41 & 0,41 & 0,41 & 0,41 & 0,41 & 0,41 & 0,41 & 0,41 & 0,41 & 0,41 & 0,41 \\
\hline Cálcio (\%) & 0,65 & 0,65 & 0,65 & 0,65 & 0,65 & 0,65 & 0,65 & 0,65 & 0,65 & 0,65 & 0,65 & 0,65 & 0,65 & 0,65 & 0,65 & 0,65 \\
\hline Proteína bruta (\%) & 20,50 & 20,50 & 20,50 & 20,50 & 20,50 & 20,50 & 20,50 & 20,50 & 20,50 & 20,50 & 20,50 & 20,50 & 20,50 & 20,50 & 20,50 & 20,50 \\
\hline Arginina digestível (\%) & 1,57 & 1,57 & 1,57 & 1,57 & 1,57 & 1,57 & 1,57 & 1,57 & 1,57 & 1,57 & 1,57 & 1,57 & 1,57 & 1,57 & 1,57 & 1,57 \\
\hline Lisina & 1,45 & 1,45 & 1,45 & 1,45 & 1,45 & 1,45 & 1,45 & 1,45 & 1,45 & 1,45 & 1,45 & 1,45 & 1,45 & 1,45 & 1,45 & 1,45 \\
\hline $\operatorname{Tr}$ & 0,97 & 0,97 & 0,97 & 0,97 & 0,97 & 0,97 & 0,97 & 0,97 & 0,97 & 0,97 & 0,97 & 0,97 & 0,97 & 0,97 & 0,97 & 0,97 \\
\hline Tript & 0,32 & 0,32 & 0,32 & 0,32 & 0,32 & 0,32 & 0,32 & 0,32 & 0,32 & 0,32 & 0,32 & 0,32 & 0,32 & 0,32 & 0,32 & 0,32 \\
\hline $\mathrm{Me}$ & 1,15 & 1,15 & 1,15 & 1,15 & & 1,15 & 1,15 & & 1,15 & 1,15 & 1,15 & & 1,15 & 1,15 & 1,15 & 1,15 \\
\hline Isoleu & 0,73 & 0,93 & 1,13 & 1,33 & 0,73 & 0,93 & 1,13 & 1,3 & 0,73 & 0,93 & 1,13 & 1,33 & 0,73 & 0,93 & 1,13 & 1,33 \\
\hline & 0,82 & 0,82 & 0,82 & 0,82 & 1,02 & 1,02 & 1,02 & 1,0 & 1,22 & 1,22 & 1,22 & 1,22 & 1,42 & 1,42 & 1,42 & 1,42 \\
\hline Leucina digestível (\%) & 1,43 & 1,43 & 1,43 & 1,43 & 1,43 & 1,43 & 1,43 & 1,43 & 1,43 & 1,43 & 1,43 & 1,43 & 1,43 & 1,43 & 1,43 & 1,43 \\
\hline Cloro ( & 0,28 & 0,28 & 0,28 & 0,28 & 0,28 & 0,28 & 0,28 & 0,28 & 0,28 & 0,28 & 0,28 & 0,28 & 0,28 & 0,28 & 0,28 & 0,28 \\
\hline Sódio (\%) & 0,22 & 0,22 & 0,22 & 0,22 & 0,22 & 0,22 & 0,22 & 0,22 & 0,22 & 0,22 & 0,22 & 0,22 & 0,22 & 0,22 & 0,22 & 0,22 \\
\hline Potássio (\% & 0,62 & 0,62 & 0,62 & 0,62 & 0,62 & 0,62 & 0,62 & 0,62 & 0,62 & 0,62 & 0,62 & 0,62 & 0,62 & 0,62 & 0,62 & 0,62 \\
\hline Balanço Eletrolítico $(\mathrm{mEq} / \mathrm{kg})$ & 174,89 & 174,91 & 175,09 & 175,20 & 174,99 & 175,09 & 175,20 & 175,30 & 175,09 & 175,20 & 175,30 & 175,43 & 175,20 & 175,32 & 175,43 & 175,45 \\
\hline
\end{tabular}

As aves foram pesadas semanalmente e, simultaneamente, foram realizadas as pesagens das rações experimentais para posterior avaliação do desempenho zootécnico.
As codornas de corte foram avaliadas por meio das variáveis: peso final, ganho de peso, consumo de ração, conversão alimentar e biomassa corporal acumulada. 
A análise estatística dos dados foi realizada por meio do método de quadrados mínimos, utilizando-se o sistema para análises estatísticas - SAEG (versão 7.1).

\section{RESULTADOS E DISCUSSÃO}

Não houve interação $(\mathrm{P}>0,05)$ para as variáveis de desempenho, no período de um a 14 dias, em função dos níveis de valina digestível (VD) e isoleucina digestível (ID), demonstrando uma atuação de maneira independente.

O consumo de ração (CR) apresentou efeito quadrático $(\mathrm{P}<0,05)$ em função dos níveis de valina e isoleucina digestível (Tab. 5). Os valores estimados de máximo CR (133,61 g/ave) foram obtidos com rações contendo $1,40 \%$ de VD e $1,26 \%$ de ID. Com base nas respostas de desempenho, o $\mathrm{CR}$ foi a única variável a apresentar ajuste dos dados pelo modelo quadrático associado ao platô do LRP, conforme metodologia descrita por Sakomura e Rostagno (2007), estimando a melhor exigência em 1,23\% de valina digestível para o consumo de $132,83 \mathrm{~g} /$ ave.

De acordo com o nível de lisina digestível utilizado na formulação das rações experimentais de $1,60 \%$, foi possível estabelecer a relação valina:lisina de $77 \%$ e isoleucina:lisina de $79 \%$. Rostagno et al. (2011) determinaram a relação valina:lisina (77\%) e isoleucina:lisina (67\%) para frangos de corte de um a 21 dias. A comparação entre os dois resultados demonstra que a relação de valina, tanto para codornas de corte quanto para frangos de corte, está bem próxima. Por outro lado, codornas apresentam maior relação isoleucina:lisina que frangos de corte.

Tabela 5. Valores médios do desempenho de codornas de corte, no período de um a 14 dias de idade, em função dos níveis de valina e isoleucina digestível

\begin{tabular}{|c|c|c|c|c|c|c|c|c|c|c|c|c|c|c|c|c|c|}
\hline \multirow{2}{*}{$\begin{array}{l}\text { VD (\%) } \\
\text { ID (\%) }\end{array}$} & \multicolumn{4}{|c|}{0,90} & \multicolumn{4}{|c|}{1,10} & \multicolumn{4}{|c|}{1,30} & \multicolumn{4}{|c|}{1,50} & \\
\hline & 0,80 & 1,00 & 1,20 & 1,40 & 0,80 & 1,00 & 1,20 & 1,40 & 0,80 & 1,00 & 1,20 & 1,40 & 0,80 & 1,00 & 1,20 & 1,40 & \\
\hline CR(g/ave) & 127,16 & 129,91 & 131,13 & 130,80 & 129,37 & 132,13 & 133,34 & 133,01 & 130,47 & 133,23 & 134,44 & 134,11 & 130,46 & 133,21 & 134,43 & 134,10 & 1,71 \\
\hline 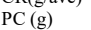 & 80,81 & 82,90 & 84,14 & 84,55 & 81,67 & 83,76 & 85,00 & 85,40 & 82,53 & 84,61 & 85,86 & 86,26 & 83,38 & 85,47 & 86,72 & 87,12 & 2,03 \\
\hline GP (g) & 71,68 & 73,83 & 75,07 & 75,43 & 72,53 & 74,67 & 75,92 & 76,27 & 73,37 & 75,51 & 76,76 & 77,11 & 74,21 & 76,35 & 77,60 & 77,96 & 2,26 \\
\hline $\mathrm{BCA}(\%)$ & 786,02 & 814,05 & 827,86 & 827,43 & 793,79 & 821,83 & 835,63 & 835,21 & 801,57 & 829,60 & 843,41 & 842,98 & 809,34 & 837,38 & 851,18 & 850,76 & 2,41 \\
\hline $\mathrm{CA}(\mathrm{g} / \mathrm{g})$ & 1,77 & 1,76 & 1,75 & 1,73 & 1,78 & 1,77 & 1,76 & 1,74 & 1,78 & 1,76 & 1,75 & 1,74 & 1,76 & 1,74 & 1,73 & 1,72 & 1,77 \\
\hline \multirow{2}{*}{\multicolumn{9}{|c|}{ Equação de regressão }} & $\mathrm{R}^{2}$ & \multicolumn{4}{|c|}{ Estimativa } & \multicolumn{4}{|c|}{ Efeito } \\
\hline & & & & & & & & & & & ID & \multirow{2}{*}{\multicolumn{2}{|c|}{ VD }} & \multicolumn{2}{|c|}{ ID } \\
\hline \multicolumn{9}{|c|}{$\mathrm{CR}=76,9776+38,8959 \mathrm{VD}-13,9151 \mathrm{VD}^{2}+48,4798 \mathrm{ID}-19,2800 \mathrm{ID}^{2}$} & 0,99 & & & & $1,26 \%$ & & & \multicolumn{2}{|c|}{ Quadrático } \\
\hline \multicolumn{9}{|c|}{$\mathrm{CR}=112,5161+18,2984 \mathrm{VD}$} & 0,99 & \multicolumn{3}{|c|}{$1,11 \%$} & (20) & \multicolumn{2}{|c|}{ LRP } & \multirow{2}{*}{\multicolumn{2}{|c|}{$\begin{array}{c}\text { NS } \\
\text { Ouadrático }\end{array}$}} \\
\hline \multicolumn{9}{|c|}{$\mathrm{PC}=60,1608+4,29292 \mathrm{VD}+29,4083 \mathrm{ID}-10,5362 \mathrm{ID}^{2}$} & 0,94 & \multicolumn{3}{|c|}{ (110 } & $1,40 \%$ & \multicolumn{2}{|c|}{ Linear } & & \\
\hline \multirow{2}{*}{\multicolumn{9}{|c|}{$\mathrm{GP}=50,3877+4,21383 \mathrm{VD}+30,8200 \mathrm{ID}-11,1737 \mathrm{ID}^{2}$}} & 0,95 & \multicolumn{3}{|c|}{--- } & $1,38 \%$ & \multicolumn{2}{|c|}{ Linear } & \\
\hline & & & & & & & & & 1,00 & & -..- & & $1,29 \%$ & \multicolumn{2}{|c|}{ Linear } & \multicolumn{2}{|c|}{$\begin{array}{l}\text { Quadratico } \\
\text { Quadrático }\end{array}$} \\
\hline
\end{tabular}

Coeficiente de variação (CV); valina digestível (VD); isoleucina digestível (ID); consumo de ração (CR); peso corporal (PC); ganho de peso (GP); biomassa corporal acumulada (BCA); conversão alimentar (CA) e não significativo (NS)

Potença (2011), ao utilizar diferentes relações de valina:lisina digestível $(66 ; 71 ; 76 ; 81$ e $86 \%)$ na dieta de frangos de corte, observou aumento linear $(\mathrm{P}<0,05)$ no ganho de peso e no consumo de ração no período de um a sete dias, sem influenciar $(\mathrm{P}>0,05)$ a conversão alimentar. No período de um a 14 dias de idade, o desempenho não foi influenciado $(\mathrm{P}>0,05)$ pela relação valina:lisina digestível, sendo indicada para essa fase a relação de $66 \%$ e nível de $0,90 \%$ de VD.

O peso corporal (PC), o ganho de peso (GP) e a biomassa corporal acumulada (BCA) aumentaram linearmente $(\mathrm{P}<0,05)$ em função dos ,iveis de isoleucina digestivel. As estimativas de niveis de isoleucina digestivel. As estimativas de (841,66\%) foram alcançadas com a utilização de rações que continham $1,40 \%, 1,38 \%$ e $1,29 \%$ de ID, respectivamente. Tomando como base o de $1,60 \%$ de lisina digestível, pode-se PC, $86 \%$ para o GP e $81 \%$ para a BCA.

Baker et al. (2002), ao estimarem as exigências de valina para frangos de corte da linhagem Ross 308, no período de oito a 21 dias de idade, observaram que as relações valina:lisina digestível de 76 e $77 \%$ proporcionaram melhor ganho de peso e conversão alimentar, respectivamente.

Não houve interação $(\mathrm{P}>0,05)$ entre valina digestível (VD) e isoleucina digestível (ID) sobre as variáveis de desempenho no período de 15 a 35 dias de idade. A ausência de interação indica que os diferentes níveis de VD e ID, adicionados às rações, agiram de maneira independente sobre 
O desempenho de codornas de corte, no período de 15 a 35 dias de idade, não foi influenciado $(\mathrm{P}>0,05)$ pelo aumento dos níveis de valina digestível (VD) e isoleucina digestível (ID) nas rações experimentais (Tab. 6).

A ausência de significância sugere que os menores níveis avaliados, de $0,82 \%$ de valina digestível e de $0,73 \%$ de isoleucina digestível, foram suficientes para atender as exigências nutricionais de codornas de corte nessa fase de crescimento.

Thornton et al. (2006), ao trabalharem com frangos de corte de 22 a 42 dias de idade, observaram aumento linear do ganho de peso das fêmeas com o aumento dos níveis de valina de $0,64 \%$ para $0,87 \%$, enquanto os machos responderam de forma quadrática, apresentando melhores resultados com $0,73 \%$ de valina.

Por outro lado, Kidd et al. (2004) verificaram que a suplementação de isoleucina em dietas com redução dos níveis proteicos (de 18,6\% para $17,5 \%$ ) resultou em ganho de peso e qualidade de carcaça de frangos semelhantes ao tratamento controle. Os autores recomendam níveis entre $0,67 \%$ e $0,71 \%$ de isoleucina na dieta para a fase de 18 a 30 dias, $0,64 \%$ e $0,66 \%$ de 30 a 42 dias e, $0,55 \%$ e $0,66 \%$ de 42 a 56 dias.

Tabela 6. Valores médios do desempenho de codornas de corte, no período de 15 a 35 dias de idade, em função dos níveis de valina e isoleucina digestível

\begin{tabular}{|c|c|c|c|c|c|c|c|c|c|c|c|c|c|c|c|c|c|}
\hline VD (\%) & & & & & & & & & & & & & & & & & $C Y$ \\
\hline ID (\%) & 0,73 & 0,93 & 1,13 & 1,33 & 0,73 & 0,93 & 1,13 & 1,33 & 0,73 & 0,93 & 1,13 & 1,33 & 0,73 & 0,93 & 1,13 & 1,33 & \\
\hline CR(g/ave) & 478,58 & 474,92 & 474,73 & 469,24 & 478,06 & 474,24 & 486,39 & 483,83 & 479,42 & 472,59 & 484,01 & 469,52 & 473,73 & 482,60 & 476,56 & 487,49 & 1,60 \\
\hline PC (g) & 230,82 & 228,45 & 227,27 & 227,20 & 229,80 & 226,57 & 229,44 & 228,61 & 230,08 & 226,08 & 228,93 & 229,30 & 226,60 & 228,45 & 230,37 & 228,32 & 1,77 \\
\hline GP (g) & 149,27 & 145,90 & 145,81 & 145,11 & 148,01 & 144,69 & 146,58 & 146,58 & 148,07 & 144,33 & 146,86 & 147,05 & 145,00 & 145,88 & 147,59 & 145,59 & 2,89 \\
\hline BCA (\%) & 183,09 & 176,74 & 179,02 & 176,79 & 180,98 & 176,73 & 176,94 & 178,70 & 180,53 & 176,56 & 178,97 & 178,81 & 177,70 & 176,69 & 178,37 & 175,98 & 3,28 \\
\hline $\mathrm{CA}(\mathrm{g} / \mathrm{g})$ & 3,21 & 3,26 & 3,26 & 3,24 & 3,23 & 3,28 & 3,32 & 3,30 & 3,24 & 3,27 & 3,30 & 3,20 & 3,27 & 3,31 & 3,23 & 3,35 & 2,38 \\
\hline
\end{tabular}

Coeficiente de variação (CV); valina digestível (VD); isoleucina digestível (ID); consumo de ração (CR); peso corporal (PC); ganho de peso (GP); biomassa corporal acumulada (BCA) e conversão alimentar (CA).

\section{CONCLUSÃO}

As exigências de valina e isoleucina digestível para o máximo desempenho de codornas de corte, no período de um a 14 dias de idade, foram de $1,50 \%$ e $1,38 \%$, respectivamente, correspondendo às relações valina:lisina de $94 \%$ e isoleucina:lisina de $86 \%$. Os menores níveis avaliados, de $0,82 \%$ de valina digestível e de $0,73 \%$ de isoleucina digestível, correspondendo às relações valina:lisina de $52 \%$ e isoleucina:lisina de $46 \%$, foram suficientes para satisfazer as exigências nutricionais das codornas de corte no período de 15 a 35 dias de idade, sem comprometer o desempenho.

\section{REFERÊNCIAS}

BAKER, D.H.; BATAL, A.B.; PARR, T.M.; AUGSPURGER, N.R. et al. Ideal ratio (relative to lysine) of tryptophan, threonine, isoleucine and valine for chicks during the second and third weeks posthatch. Poult. Sci., v.81, p.485-494, 2002.
FREITAS, A.C.; FUENTES, M.F.F.; FREITAS, E.R. et al. Níveis de proteína bruta e energia metabolizável na ração de codornas de corte. Rev. Bras. Zootec., v.35, p.1705-1710, 2006.

FUGIKURA, W.S. Situação e perpectivas da coturnicultura no Brasil. In: SIMPÓSIO INTERNCIONAL DE COTURNICULTURA, 1., 2002, Lavras. Anais... Lavras: Universidade Federal de Lavras, 2002. p.1.

GARCIA, E.A. Codornas para produção de carne. In: SIMPÓSIO INTERNACIONAL DE COTURNICULTURA, 1., 2002, Lavras. Anais... Lavras: Universidade Federal de Lavras, 2002. p.97-108.

KIDD, M.T.; BURNHAM, D.J.; KERR, B.J. Isoleucine needs of Ross male broilers. Br. Poult. Sci., v.45, p.67-75, 2004.

MONGIN P. Recent advances in dietary ânioncátion balance: applications in poultry. Proc. Nutr. Soc., v.40, p.285-294, 1981.

POTENÇA, A. Relação valina: lisina digestível em rações para frangos de corte. 2011. 105f. Tese (Doutorado em Zootecnia) - Universidade Estadual de Maringá, Maringá, PR. 
REZENDE, M.J.M.; FLAUZINA, L.P.; McMANUS,C.; OLIVEIRA, L.Q.M. Desempenho produtivo e biometria das vísceras de codornas francesas alimentadas com diferentes níveis de energia metabolizável e proteína bruta. Acta. Sci. Anim. Sci., v.26, p.353-358, 2004.

ROSTAGNO, H.S.; ALBINO, L.F.L.; DONZELE, J.L.; GOMES, P.C. et al. Tabelas brasileiras para aves e suínos: composição de alimentos e exigências nutricionais. 3.ed. Viçosa: Universidade Federal de Viçosa, 2011. 252p.

SAKOMURA, N.K.; ROSTAGNO, H.S. Métodos de pesquisa em nutrição para monogástricos. Jaboticabal: Funep, 2007. 283p.

SCHERER, C. Exigência nutricional de energia metabolizável, lisina digestível $e$ metionina+cistina digestível para codornas de corte em fase de crescimento. 2009. 118f. Tese (Doutorado em Zootecnia) - Universidade Estadual de Maringá, Maringá, PR.
SHIMOMURA, Y.; YAMAMOTO, Y.; BAJOTTO, G. S.; SATO, J. et al. Nutraceutical effects of branched-chain amino acids on skeletal muscle. J. Nutr., v.136, p.529-532, 2006.

SILVA, R.M.; FURLAN, A.C.; TON, A.P.S.; MARTINS, E. N. et al. Exigências nutricionais de cálcio e fósforo de codornas de corte em crescimento. Rev. Bras. Zootec., v.38, p.15091524, 2009.

THRONTON, S.A.; CORZO, A.; PHARR, G.T., DOZIER, W.A. et al. Valine requirements for immune and growth responses in broilers from 3 to 6 weeks of age. Br. Poult. Sci., v.47, p.190199, 2006.

TON, A.P.S. Exigências de treonina e triptofano digestível para codornas de corte. 2010. 109f. Tese (Doutorado em Zootecnia) - Universidade Estadual de Maringá, Maringá, PR.

TUTTLE, W.L.; BALLOUN, S.L. Leucine, isoleucine and valine interactions in turkey poults. Poult. Sci., v.55, p.1737-1743, 1976. 